\title{
Combined Effects of Bottom Ash and Expanded Polystyrene on Light-weight Concrete Properties
}

\author{
Lam Tang Van *, Tho Vu Dinh, Dien Vu Kim, Boris Bulgakov, Olga Aleksandrova and \\ Sophia Bazhenova
}

Moscow State University of Civil Engineering, Yaroslavskoe shosse, 26, Moscow, 129337, Russia

\begin{abstract}
The benefits of using waste materials as a partial replacement for cement in high performance concrete are also discussed. This paper presents the combined effects of bottom ash TPP "Vung Ang" and expanded polystyrene aggregate on different the properties of light-weight concrete. Twenty different concrete mixtures with a water to cement ratio of 0.4 and superplasticizer to cement ratio of 0.015 were used. On the one hand, the EPS was partially replaced with $(0 \div 40) \%$ by volume of concrete mixture. On the other hand, the fine aggregate was replaced with $(0 \div 30) \%$ by mass of BA TPP "Vung Ang". The engineering properties, including workability, density and compressive strength of light-weight concrete were investigated at different curing times. The level of decrease in the strength depends upon the replacement level of EPS and BA. Specifically, the concrete containing $40 \%$ EPS and $30 \%$ BA at 28 days of age decrease in average density and strength were $43.2 \%$ and $26.4 \%$, respectively, in comparison with the control concrete.
\end{abstract}

\section{Introduction}

Recent years in Vietnam, with the recent rapid developments of High-Rise buildings in urban areas, larger and longer spanning concrete structures, better concrete performance with higher strength, lower density, low thermal conductivity and other properties is urgently required. Light-weight concrete has been used for structural purposes to meet these requirements and become an environmentally-sustainable material $[1,2]$.

Among the various types of light-weight concretes that have been proposed, those obtained by mixing high-performance cement-based composites with expanded polystyrene (EPS) are particularly interesting for their excellent properties, such as the ability to be fabricated on the construction site and the tailoring of properties by varying mineral additives and superplasticizers, as well as good energy-absorbing characteristics [3].

As we know, EPS aggregate is a light-weight material. Therefore, it can be partially replaced volume of concrete mixture to produce light-weight concrete, which is an important material in reducing the dead-weight of concrete complying with special concrete structures of high-rise buildings $[4,5]$.

*Corresponding author: lamvantang@gmail.com 
In addition, some studies [6, 7] have reported the importance of using fly ash, rice husk ash and bottom ash in concrete which can save a significant amount of energy and cost in cement manufacturing and also it can improve engineering properties of concrete by replacing with normal cement.

Besides that, the annual amount of industrial waste is more than 150 million tons in Vietnam. In which, metallurgical slag is about $45 \div 55$ million tons, ash and slag TPP is nearly $50 \div 60$ million tons [8, 9]. In 2016, TPP "Vung Ang" produces about 3000 tons of ash and slag waste daily. In addition, an enormous number of gaseous substances and solid particles formed as a result of solid fuel combustion enter the atmosphere through the smokestacks of this power plants, which have caused seriously environmental pollution in Vietnam central provinces.

Because the aim of this study was to investigate the combined effects of bottom ash TPP "Vung Ang" and expanded polystyrene aggregate on the properties of light-weight concrete, which are intended for light-weight concrete blocks with low thermal conductivity in the High-Rise Construction.

\section{Experimental details}

\subsection{Materials}

1. Good quality river sand was used as a fine aggregate, which produced from the quartz sand (QS) of "Lo River" (Vietnam). The fineness modulus $\mathrm{M}_{\mathrm{K}}=3.1$, specific gravity and dry density are $2.65 \mathrm{~g} / \mathrm{cm}^{3}$ and $1650 \mathrm{~kg} / \mathrm{m}^{3}$. The particle size distributions details of fine aggregates is shown in Figure 1

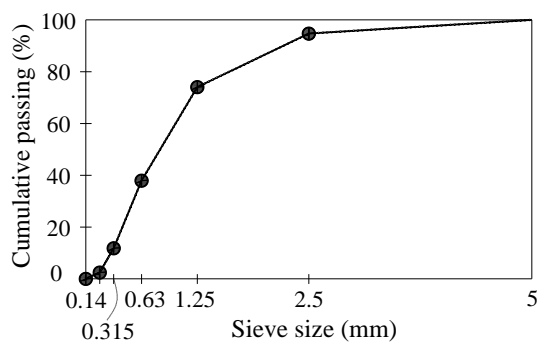

Fig. 1. Sieving analysis of good quality river sand

2. The cement used was ordinary Portland cement (OPC) (40 Grade), manufactured at "Tam Diep" factory (Vietnam), specific weight of $3.14 \mathrm{~g} / \mathrm{cm}^{3}$. The experimental results of physical and mechanical properties of cement are presented in Table 1 and the results of the chemical compositions are presented in Table 2.

Table 1. Physical and mechanical properties of ordinary Portland cement

\begin{tabular}{|c|c|c|c|c|c|c|c|c|}
\hline \multirow{2}{*}{$\begin{array}{l}\text { Specific } \\
\text { weight } \\
\left(\mathrm{g} / \mathrm{cm}^{3}\right)\end{array}$} & \multirow{2}{*}{$\begin{array}{c}\text { Retained content } \\
\text { on sieve } 0.09 \\
\text { mm }(\%)\end{array}$} & \multirow{2}{*}{$\begin{array}{l}\text { Surface } \\
\text { area } \\
\left(\mathrm{cm}^{2} / \mathrm{g}\right)\end{array}$} & \multicolumn{2}{|c|}{$\begin{array}{l}\text { Time of setting } \\
\text { (min) }\end{array}$} & \multicolumn{3}{|c|}{$\begin{array}{c}\text { Compressive strength } \\
(\mathrm{MPa})\end{array}$} & \multirow{2}{*}{$\begin{array}{c}\text { Standard } \\
\text { consistency } \\
(\%)\end{array}$} \\
\hline & & & Initial & Final & 3 days & 7 days & 28 days & \\
\hline 3.14 & 5.15 & 3620 & 125 & 360 & 20.4 & 35.2 & 50.4 & 29.5 \\
\hline
\end{tabular}

3. Bottom Ash (BA) TPP "Vung Ang" (Vietnam) Class F with specific weight of 2.22 $\mathrm{g} / \mathrm{cm}^{3}$, the volume of natural porous state are $860 \mathrm{~kg} / \mathrm{m}^{3}$ and water demand of $27.8 \%$. Retained content on sieve $0.09 \mathrm{~mm}$ is $10.5 \%$. The analysis results of chemical compositions of bottom ash TPP "Vung Ang" are presented in Table 2 and figure 2.

Table 2. Chemical properties of ordinary Portland cement and bottom ash TPP "Vung Ang"

\begin{tabular}{|c|c|c|c|c|c|c|c|c|}
\hline Materials & $\mathrm{SiO}_{2}$ & $\mathrm{Al}_{2} \mathrm{O}_{3}$ & $\mathrm{Fe}_{2} \mathrm{O}_{3}$ & $\mathrm{CaO}$ & $\mathrm{MgO}$ & $\mathrm{SO}_{3}$ & $\mathrm{LOI}^{(\mathrm{a})}$ & other \\
\hline Portland cement & 20.5 & 4.4 & 5.2 & 61.3 & 2.5 & 3.7 & 2.1 & 0.3 \\
\hline Bottom Ash & 62.5 & 14.1 & 8.5 & 3.2 & 4.1 & 1.7 & 3.4 & 2.5 \\
\hline
\end{tabular}

Note: ${ }^{(a)}$ LOI - Loss on ignition.

4. Expanded polystyrene (EPS) was used as a light-weight aggregate with the size of 2.5 $\div 5 \mathrm{~mm}$. Its dry density is $20.5 \mathrm{~kg} / \mathrm{m}^{3}$ (figure 3 ). 
5. Superplasticizer SR 5000F "SilkRoad" (SR5000) (Korea). It is a new generation chemical additives based on polycarboxylate ethers with specific weight of $1.1 \mathrm{~g} / \mathrm{cm}^{3}$ at $20 \pm 5^{\circ} \mathrm{C}$.

6. Ordinary clean tap water (W) was used for both mixing concrete and curing of test specimens.

\subsection{Methods}

On the one hand, this paper will analyze the chemical composition and the grain composition of bottom ash TPP "Vung Ang" by laser granulometry method. On the other hand, calculation method of concrete mixture composition is applied in accordance with absolute volume method. The flow ability of concrete mixture is determined by standard slump cone with dimensions of 100x200x300 $\mathrm{mm}$. The compressive strength of light-weight concrete is determined by a $70 \times 70 \times 70 \mathrm{~mm}$ cube specimen by Russian standard GOST 10180-2012 at the ages of 3, 7, 14 and 28 days (Figures 4 and 5). These cube samples are demolded after 24 hours later casting and placed in a $20{ }^{\circ} \mathrm{C}$ water curing tank until the experiments. Besides, the dry density of concrete is determined by standard BS EN 12390-7:2009.
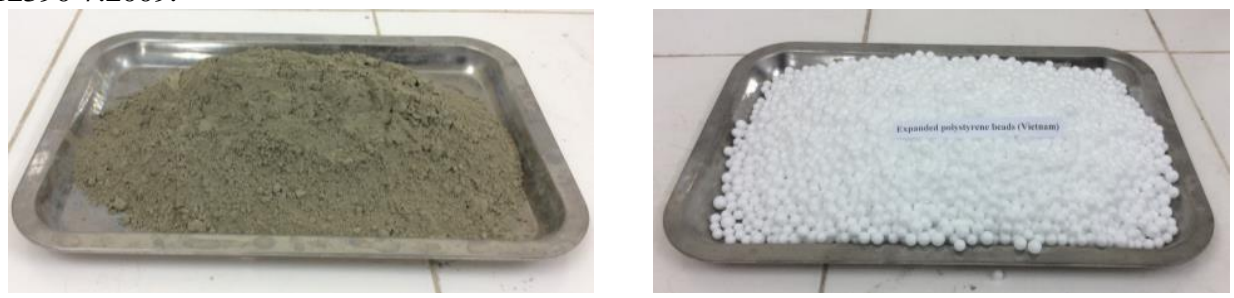

Fig. 2. Bottom ash TPP "Vung Ang"

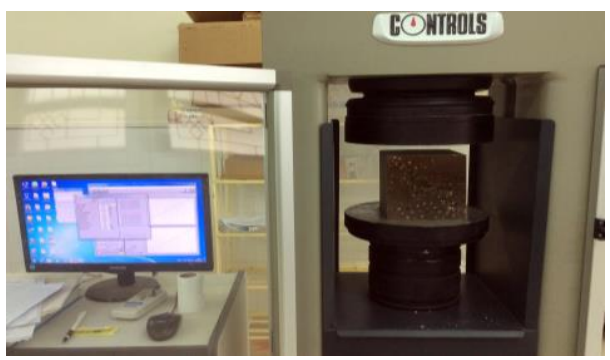

Fig. 3. Expanded polystyrene

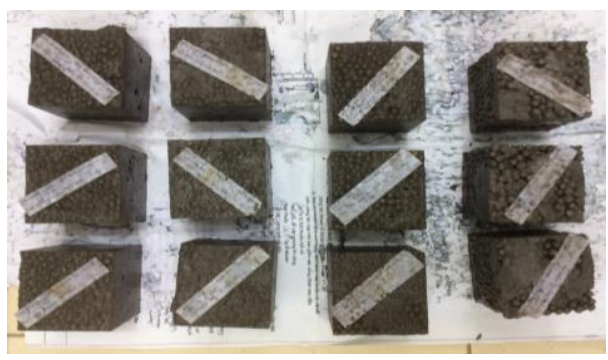

Fig. 4. Failure of concrete specimen under compression Fig. 5. Specimens of light-weight concrete

\subsection{Concrete Mixtures}

It is necessary to determine the concrete mixture compositions for the light-weight concrete production, which are intended for light-weight concrete blocks with low thermal conductivity in the High-Rise Construction in Northern Vietnam.

The initial ratios of raw materials by weight in concrete mixtures for the production of light-weight concrete are given in Table 3.

Table 3. Ratios of raw materials used in preliminary composition

\begin{tabular}{|c|c|c|c|c|}
\hline Ratios & $\frac{\mathrm{W}}{\mathrm{OPC}}$ & $\frac{\mathrm{QS}}{\mathrm{OPC}}$ & $\frac{\mathrm{SR} 5000}{\mathrm{OPC}}$ & $\begin{array}{c}\text { Volume of air in } \\
\text { concrete }\end{array}$ \\
\hline Value & 0.4 & 1.4 & $1.5 \%$ & $2 \%$ \\
\hline
\end{tabular}

Note: $B I D-$ bind: $B I D=P C+B A$

Based on the rate on and combined with methods could work absolute, the preliminary of the material compositions in the dry state of the concrete mixture (control mixture) is shown in Table 4.

A total of twenty concrete mixtures with varying amounts of EPS and BA were made for this experiment. The control concrete mixture (mix. 1) had a proportion as in table 3 . 
On the one hand, the volume fresh concrete was replaced with $0 \%, 10 \%, 20 \%, 30 \%$ and $40 \%$ by volume of EPS aggregate. On the other hand, the fine aggregate was replaced with $0 \%, 10 \%, 20 \%$ and $30 \%$ by mass of BA TPP "Vung Ang".

According to $[4,5]$, choosing lower substitutions of EPS in concrete mixture is within satisfactory limits. However, one of the main goals of the present work is to utilise as much EPS aggregate as possible, solving the disposal problem of waste expanded polystyrene foam and producing light-weight concrete blocks with low thermal conductivity in construction the High-Rise buildings.

The ratios $\frac{\mathrm{W}}{\mathrm{OPC}}$ and $\frac{\mathrm{SR} 5000}{\mathrm{OPC}}$ of 0.4 and 0.015 respectively were kept constant for all mixtures and no adjustment to the water content was made for all mixtures. In this study, the superplasticizer SR 5000F "SilkRoad" has been used to reduce the $\frac{\mathrm{W}}{\mathrm{OPC}}$ ratio and to increase workability of concrete mixtures. Details about all concrete mixtures used in this work can be found in Table 4.

Table 4. Mix compositions and properties of fresh concrete

\begin{tabular}{|c|c|c|c|c|c|c|c|c|c|c|}
\hline \multirow{2}{*}{$\begin{array}{c}\text { Mix } \\
\text { No. }\end{array}$} & $\begin{array}{c}\text { EPS } \\
(\%)\end{array}$ & BA (\%) & \multicolumn{6}{|c|}{ Compositions of concrete mixture $\left(\mathrm{kg} / \mathrm{m}^{3}\right)$} & \multicolumn{2}{|c|}{ Properties of fresh } \\
\hline 1 & 0 & 0 & 781 & 0 & 11.7 & 1094 & 313 & 0 & 2200 & 125 \\
\hline 2 & 0.1 & 0 & 702 & 0 & 10.5 & 983 & 281 & 2.05 & 1979 & 130 \\
\hline 3 & 0.2 & 0 & 623 & 0 & 9.3 & 872 & 249 & 4.1 & 1757 & 145 \\
\hline 4 & 0.3 & 0 & 543 & 0 & 8.2 & 761 & 217 & 6.15 & 1536 & 180 \\
\hline 5 & 0.4 & 0 & 464 & 0 & 7 & 650 & 186 & 8.2 & 1315 & 185 \\
\hline 6 & 0 & 0.1 & 781 & 98 & 11.7 & 983 & 313 & 0 & 2187 & 108 \\
\hline 7 & 0.1 & 0.1 & 702 & 88 & 10.5 & 883 & 281 & 2.05 & 1967 & 125 \\
\hline 8 & 0.2 & 0.1 & 623 & 78 & 9.3 & 783 & 249 & 4.1 & 1747 & 162 \\
\hline 9 & 0.3 & 0.1 & 543 & 68 & 8.2 & 683 & 217 & 6.15 & 1527 & 154 \\
\hline 10 & 0.4 & 0.1 & 464 & 58 & 7 & 584 & 186 & 8.2 & 1307 & 165 \\
\hline 11 & 0 & 0.2 & 781 & 178 & 11.7 & 892 & 313 & 0 & 2176 & 92 \\
\hline 12 & 0.1 & 0.2 & 702 & 160 & 10.5 & 801 & 281 & 2.05 & 1957 & 110 \\
\hline 13 & 0.2 & 0.2 & 623 & 142 & 9.3 & 711 & 249 & 4.1 & 1738 & 145 \\
\hline 14 & 0.3 & 0.2 & 543 & 124 & 8.2 & 620 & 217 & 6.15 & 1520 & 150 \\
\hline 15 & 0.4 & 0.2 & 464 & 106 & 7 & 530 & 186 & 8.2 & 1301 & 156 \\
\hline 16 & 0 & 0.3 & 781 & 245 & 11.7 & 817 & 313 & 0 & 2167 & 85 \\
\hline 17 & 0.1 & 0.3 & 702 & 220 & 10.5 & 734 & 281 & 2.05 & 1949 & 102 \\
\hline 18 & 0.2 & 0.3 & 623 & 195 & 9.3 & 651 & 249 & 4.1 & 1731 & 110 \\
\hline 19 & 0.3 & 0.3 & 543 & 170 & 8.2 & 568 & 217 & 6.15 & 1513 & 121 \\
\hline 20 & 0.4 & 0.3 & 464 & 146 & 7 & 485 & 186 & 8.2 & 1295 & 128 \\
\hline
\end{tabular}

\section{Test results and Discussion}

\subsection{The workability of concrete mixture}

The slump cone values of the fresh concretes containing varying amounts of EPS aggregates and BA are presented in Table 4. The slump values were between 85 and $185 \mathrm{~mm}$. 
The workability of concrete mixtures containing $0 \%$ EPS (mixtures No.1, 6, 11 and 16) werein the range of $85 \div 125 \mathrm{~mm}$ and satisfying, and processes of casting, compaction, curing and finishability were performed easily. By increasing the EPS content, the workability of concrete mixtures increased. The increasing of consistency continued up to $40 \%$ EPS content. This was mainly due to EPS particles are hydrophobic and resist absorption of the mixture's water. It is also partly due to the influence of the use of the superplasticizer SR 5000F "SilkRoad".

The slump values were in the range of $125 \div 185 \mathrm{~mm}$ for concrete without BA and decreased to the range of $85 \div 128 \mathrm{~mm}$ with $30 \% \mathrm{BA}$. According to [2, 4], the concrete containing BA will cause an increase in consistency at a constant $\frac{\mathrm{W}}{\mathrm{OPC}}$ ratio. However, the fine aggregate was replaced with $0 \%$, $10 \%, 20 \%$ and $30 \%$ by mass of BA TPP "Vung Ang", which has more surface area and porosity and increases the water demand, the fresh concretes' slump values decreased with an increase in bottom ash.

\subsection{Effect of EPS and BA on density of light-weight concrete}

The density of light-weight concretes complied with BS EN 12390-7:2009 containing different contents of EPS and BA is presented in Table 5 and Figure 5. The density values were in the range of $1235.4 \div 2188.9 \mathrm{~kg} / \mathrm{m}^{3}$.

Table 5. Density of light-weight concretes

\begin{tabular}{|c|c|c|c|c|c|}
\hline \multirow{2}{*}{$\begin{array}{c}\text { Mix } \\
\text { No. }\end{array}$} & \multirow{2}{*}{ EPS $(\%)$} & \multirow{2}{*}{ BA $(\%)$} & \multicolumn{3}{|c|}{ Density of concrete at 28 days $\left(\mathrm{kg} / \mathrm{m}^{3}\right)$} \\
\cline { 4 - 6 } & & 1 & 2 & 3 \\
\hline 1 & 0 & 0 & 2180.6 & 2186.5 & 2188.9 \\
\hline 2 & 0.1 & 0 & 1955.2 & 1960.7 & 1958.3 \\
\hline 3 & 0.2 & 0 & 1725.6 & 1731.5 & 1728.4 \\
\hline 4 & 0.3 & 0 & 1520.3 & 1518.5 & 1516.7 \\
\hline 5 & 0.4 & 0 & 1285.6 & 1280.9 & 1281.3 \\
\hline 6 & 0 & 0.1 & 2155.5 & 2161.7 & 2168.4 \\
\hline 7 & 0.1 & 0.1 & 1951.3 & 1942.7 & 1948.8 \\
\hline 8 & 0.2 & 0.1 & 1715.6 & 1711.9 & 1722.8 \\
\hline 9 & 0.3 & 0.1 & 1500.4 & 1508.3 & 1502.9 \\
\hline 10 & 0.4 & 0.1 & 1256.8 & 1261.7 & 1260.1 \\
\hline 11 & 0 & 0.2 & 2145.10 & 2137.80 & 2142.6 \\
\hline 12 & 0.1 & 0.2 & 1940.20 & 1935.60 & 1932.9 \\
\hline 13 & 0.2 & 0.2 & 1710.50 & 1708.40 & 1705.7 \\
\hline 14 & 0.3 & 0.2 & 1495.70 & 1492.40 & 1490.7 \\
\hline 15 & 0.4 & 0.2 & 1252.80 & 1250.90 & 1251.6 \\
\hline 16 & 0 & 0.3 & 2134.60 & 2142.70 & 2145.1 \\
\hline 17 & 0.1 & 0.3 & 1923.50 & 1927.30 & 1918.6 \\
\hline 18 & 0.2 & 0.3 & 1695.20 & 1699.70 & 1700.1 \\
\hline 19 & 0.3 & 0.3 & 1475.60 & 1478.40 & 1480.2 \\
\hline 20 & 0.4 & 0.3 & 1245.70 & 1242.60 & 1235.4 \\
\hline
\end{tabular}




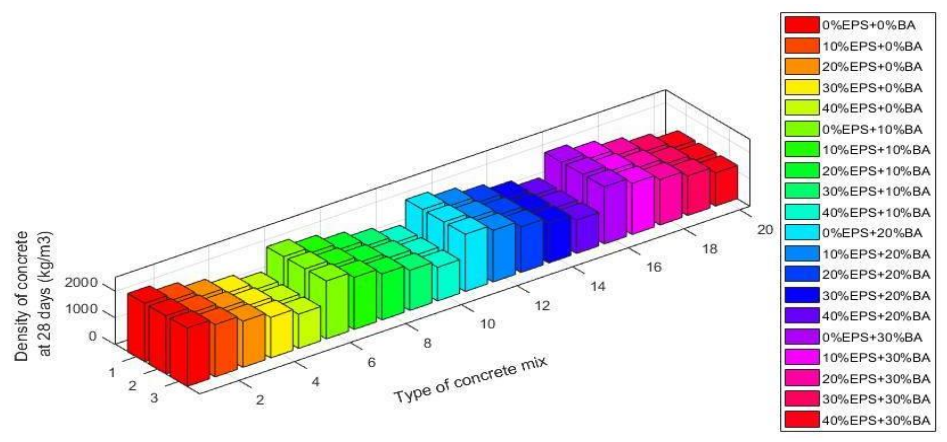

Fig. 5. Density of light-weight concrete at 28 days

The density values in Table 5 and Figure 5, shows that the density of concretes decreased with increasing in EPS contents in types of concrete. This is because the density of EPS aggregates was much less than that of natural aggregates (Table 2). According to Russian standard GOST 25820-2014, light-weight concrete is the concrete with a dry density between 500 and $1800 \mathrm{~kg} / \mathrm{m}^{3}$. Thus, in the case of present investigation the concrete incorporating $20 \%$ EPS by volume concrete mixture and higher can be considered as light-weight concrete.

Increasing the replacement level of BA with fine aggregate had little effect on the density of concretes. The density of light-weight concretes appears to decrease with an increase in the BA content. Specifically, the density of control mixture (0\% EPS + 0\% BA) was $2188.9 \mathrm{~kg} / \mathrm{m}^{3}$, which decreased to $2145.1 \mathrm{~kg} / \mathrm{m}^{3}$ with $30 \%$ BA content in concrete. A recent study [10] observed that the low density of light-weight concrete containing BA is probably related to the higher air content and lack of structure of BA.

\subsection{Effect of EPS and BA on compressive strength of concrete}

The compressive strength of concretes containing varying amounts of EPS and BA at different curing times is shown in Table 6 and illustrated in Figure 6 and 7. The compressive strength was in the range of $15.4 \div 31 \mathrm{MPa}$ at 3 days curing time and $37.6 \div 70.5 \mathrm{MPa}$ at 28 days curing age.

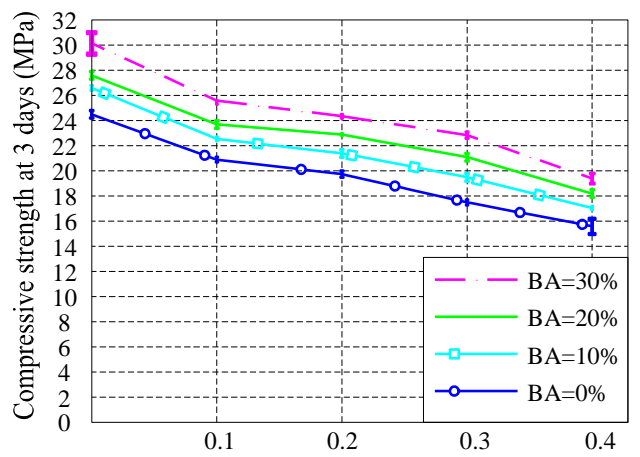

EPS volume of concrete mixture (\%)

a). Strength of concrete at age 3 -days

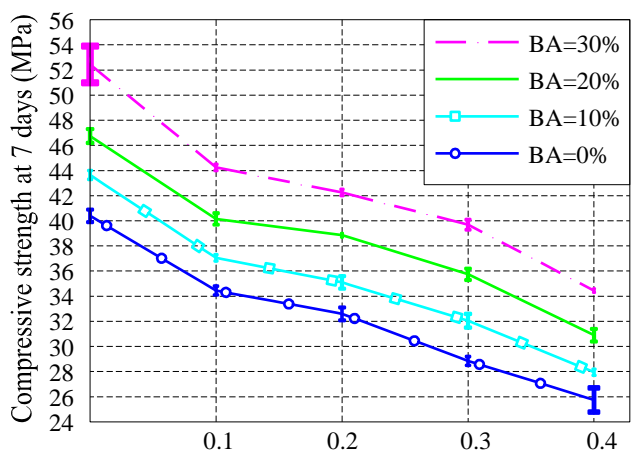

EPS volume of concrete mixture (\%)

b). Strength of concrete at age 7-days

Fig. 6. Effect of EPS and BA on concrete compressive strength at ages 3 and 7 days 


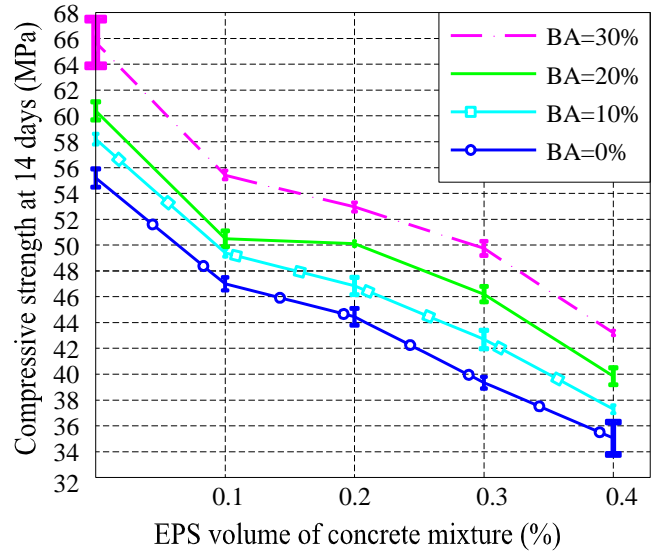

a). Strength of concrete at age 14-days

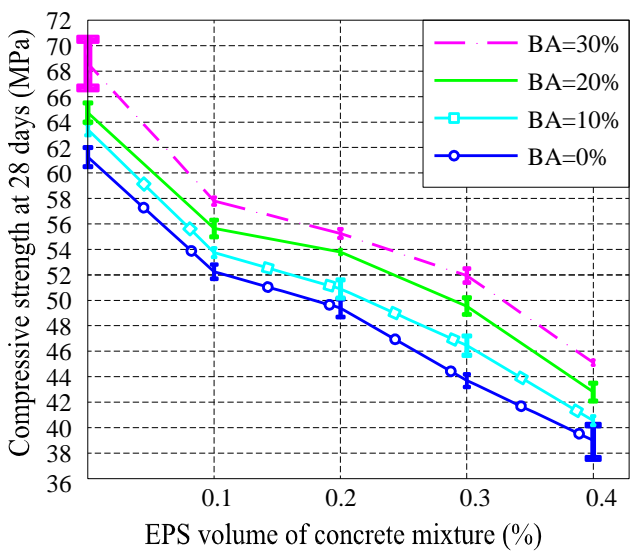

b). Strength of concrete at age 28-days

Fig. 7. Effect of EPS and BA on concrete compressive strength at ages 14 and 28 days

Table 6. Compressive strength of concrete at different curing ages

\begin{tabular}{|c|c|c|c|c|c|c|c|c|c|c|c|c|c|c|}
\hline Mix & EPS & BA & \multicolumn{10}{|c|}{ Compressive strength concrete (MPa) } \\
\cline { 5 - 18 } & $(\%)$ & \multicolumn{3}{|c|}{3 days } & \multicolumn{3}{|c|}{7 days } & \multicolumn{3}{|c|}{14 days } & \multicolumn{3}{|c|}{28 days } \\
\hline 1 & 0 & 0 & 24.2 & 24.8 & 24.5 & 39.9 & 40.9 & 40.4 & 54.5 & 55.8 & 55.1 & 60.5 & 62.0 & 61.2 \\
\hline 2 & 0.1 & 0 & 21.1 & 20.7 & 20.8 & 34.8 & 34.1 & 34.4 & 47.5 & 46.5 & 46.9 & 52.8 & 51.7 & 52.1 \\
\hline 3 & 0.2 & 0 & 19.5 & 19.7 & 20.0 & 32.1 & 32.5 & 33.1 & 43.8 & 44.4 & 45.1 & 48.7 & 49.3 & 50.1 \\
\hline 4 & 0.3 & 0 & 17.3 & 17.7 & 17.6 & 28.5 & 29.2 & 29.0 & 38.9 & 39.8 & 39.5 & 43.2 & 44.2 & 43.9 \\
\hline 5 & 0.4 & 0 & 15.4 & 15.0 & 16.2 & 25.3 & 24.8 & 26.7 & 34.6 & 33.8 & 36.4 & 38.4 & 37.6 & 40.4 \\
\hline 6 & 0 & 0.1 & 26.4 & 26.8 & 26.6 & 43.3 & 44.0 & 43.7 & 57.8 & 58.6 & 58.3 & 62.8 & 63.7 & 63.4 \\
\hline 7 & 0.1 & 0.1 & 22.7 & 22.4 & 22.6 & 37.3 & 36.8 & 37.1 & 49.8 & 49.1 & 49.5 & 54.1 & 53.4 & 53.8 \\
\hline 8 & 0.2 & 0.1 & 21.1 & 21.7 & 21.4 & 34.6 & 35.6 & 35.1 & 46.2 & 47.5 & 46.8 & 50.2 & 51.6 & 50.9 \\
\hline 9 & 0.3 & 0.1 & 19.2 & 19.8 & 19.5 & 31.5 & 32.6 & 32.1 & 42.0 & 43.4 & 42.8 & 45.7 & 47.2 & 46.5 \\
\hline 10 & 0.4 & 0.1 & 17.0 & 16.9 & 17.2 & 27.9 & 27.7 & 28.2 & 37.3 & 37.0 & 37.6 & 40.5 & 40.2 & 40.9 \\
\hline 11 & 0 & 0.2 & 27.3 & 27.3 & 27.9 & 46.2 & 46.2 & 47.3 & 59.7 & 59.6 & 61.0 & 64.1 & 64.0 & 65.5 \\
\hline 12 & 0.1 & 0.2 & 23.4 & 23.8 & 24.0 & 39.7 & 40.3 & 40.6 & 51.2 & 52.0 & 52.5 & 55.0 & 55.8 & 56.3 \\
\hline 13 & 0.2 & 0.2 & 22.8 & 23.0 & 22.8 & 38.7 & 39.0 & 38.7 & 49.9 & 50.3 & 49.9 & 53.6 & 54.0 & 53.6 \\
\hline 14 & 0.3 & 0.2 & 20.8 & 21.4 & 20.9 & 35.3 & 36.2 & 35.4 & 45.6 & 46.8 & 45.7 & 48.9 & 50.2 & 49.1 \\
\hline 15 & 0.4 & 0.2 & 17.9 & 18.5 & 18.2 & 30.4 & 31.4 & 30.9 & 39.2 & 40.5 & 39.9 & 42.1 & 43.5 & 42.8 \\
\hline 16 & 0 & 0.3 & 29.3 & 30.0 & 31.0 & 51.0 & 52.2 & 53.9 & 63.9 & 65.3 & 67.5 & 66.7 & 68.2 & 70.5 \\
\hline 17 & 0.1 & 0.3 & 25.4 & 25.6 & 25.3 & 44.2 & 44.4 & 44.0 & 55.4 & 55.7 & 55.1 & 57.8 & 58.1 & 57.5 \\
\hline 18 & 0.2 & 0.3 & 24.5 & 24.2 & 24.2 & 42.5 & 42.1 & 42.0 & 53.3 & 52.7 & 52.6 & 55.6 & 55.0 & 54.9 \\
\hline 19 & 0.3 & 0.3 & 22.6 & 23.1 & 23.0 & 39.3 & 40.2 & 40.0 & 49.2 & 50.3 & 50.1 & 51.4 & 52.5 & 52.3 \\
\hline 20 & 0.4 & 0.3 & 19.9 & 19.8 & 19.8 & 34.7 & 34.3 & 34.4 & 43.4 & 43.0 & 43.1 & 45.3 & 44.9 & 45.0 \\
\hline
\end{tabular}

The compressive strength is decreased as the EPS aggregate content in concrete mixture is increased. For example, the average compressive strength for the control concrete $(0 \%$ EPS $+0 \% \mathrm{BA}$ ) was $61.23 \mathrm{MPa}$ at 28 days of age and this decreased to $38.8 \mathrm{MPa}$ for the concrete containing $40 \%$ EPS $+0 \%$ BA at the same age; the decrease in strength was about $36,6 \%$.

The lower strength of light-weight concretes may be due to two factors: the first factor may be the lack of natural coarse aggregate in the concrete, as an investigation [4] reported that the concrete mixes containing coarse aggregate showed an increase in strength and a slight increase in density. Another factor may be the replacement of volume concrete mixture with EPS and the resulting increase in the surface area of fine particles, which can lead to weakening of interfacial transition zones between the fine aggregate and the cement 
paste. It is well known that the density of concrete has a significant influence on its strength. The strength of light-weight concretes decreased with the decrease in density of the concrete, as expected.

In the results presented in the published studies [12, 13], showed that the strength of control and light-weight concretes decreased with an increase in BA content. But in this study with the ratios water/ordinary Portland cement of 0.4 and was kept constant for all mixtures and no adjustment to the water content was made for all mixtures. Further the fine aggregate was replaced with $(0 \div 30) \%$ by mass of BA TPP «Vung Ang» - active mineral additives. Therefore, when increase in BA content, the concrete compressive strength also increases, but not much else. The average strength for the control concrete $(40 \%$ EPS + $0 \% \mathrm{BA}$ ) was $38.8 \mathrm{MPa}$ at 28 days of age and this increased to $45.067 \mathrm{MPa}$ for the concrete containing (40\% EPS $+30 \% \mathrm{BA})$ at the same age; the increase percentage in strength was about $16 \%$. The concrete containing high contents of EPS and BA can be used in lightweight concrete blocks with low thermal conductivity in the High-Rise buildings.

\section{Conclusion}

Experimental study was carried out in the laboratory of Hanoi University of Mining and Geology to find out the effect of expanded polystyrene and bottom ash TPP "Vung Ang" on the light-weight concrete properties. The absolute volume method was used to determine the concrete mixture compositions. Concrete mix containing $(0 \div 40) \%$ EPS by volume concrete mixture and $(0 \div 30) \% \mathrm{BA}$ mass of fine aggregate were used in the study. The following conclusions are drawn from the experimental results:

1. By increasing EPS and BA in concrete the density and compressive strength decrease. The level of decrease in the strength depends upon the replacement level of EPS and BA. For example, the concrete containing $40 \%$ EPS and $30 \%$ BA at 28 days of age decrease in average density and strength were $43.2 \%$ and $26.4 \%$, respectively, in comparison with the control concrete.

2. According to Russian standard GOST 25820-2014, in this investigation, the concrete incorporating $20 \%$ EPS by volume concrete mixture and higher can be considered as lightweight concrete.

3. The novel concrete produced in the present study can be used in light-weight concrete blocks with low thermal conductivity in the High-Rise buidings in Vietnam.

The Faculty of Civil Engineering's laboratory of Hanoi University of Mining and Geology (Vietnam) is gratefully acknowledged.

\section{References}

1. P.K. Mehta, In Proceedings of the VII. AIMAT Congress, Ancona, Italy, (2004)

2. C. Meng. Bing, Fang. Meng. Congqi, Constr. Mate., 164. (2011)

3. B. Chen, J. Liu, Cem. Concr. Res. (2004)

4. DS. Babu, KG. Babu and TH. Wee, Cem. Concr. Com. (2006)

5. M. A. Herki Bengin, Buil, 7 (2017), doi:10.3390/buildings7030077.

6. T. V. Lam, B. Bulgakov, Y. Bazhenov, O. Aleksandrova, P. N. Anh, IOP Conf., 365 (2018), doi:10.1088/1757-899X/365/3/032007

7. T. V. Lam, B. I. Bulgakov, O. V. Aleksandrova, O. A. Larsen., P. N. Anh, E3S Web of Conf., 33, (2018), https://doi.org/10.1051/e3sconf/20183302030 
8. T. V. Lam, B. I. Bulgakov, O. V. Aleksandrova, O .A. Larsen, Scie and theor jour., 6 (2017), DOI: 10.12737/article_5926a059214ca0.89600468

9. T. V. Lam, N. T. Chuc, N. X. Hung, D. V. Phi, B. I. Bulgakov, S. I. Bazhenova, MATEC Web of Conf (2018),. DOI: 10.1051/matecconf/201819303024.

10. R. Demirboga, R. Gül, Cem. Concr., 33 (2003)

11. K. Miled, K. Sab, R. Le Roy, Exper inves and mode. Mechan. Mate., 39 (2007)

12. D. Babu. Ganesh, K. Babu. Ganesh, H. T. Wee, Cem. Concr. Res., 35 (2005)

13. R. Demirboga, I. Türkmen, B. M. Karakoç,. Cem. Concr., 34 (2004) 